Research Article

\title{
Coupling Technology of Deep-Hole Presplitting Blasting and Hydraulic Fracturing Enhance Permeability Technology in Low-Permeability and Gas Outburst Coal Seam: A Case Study in the No. 8 Mine of Pingdingshan, China
}

\author{
Wei Wang, ${ }^{1,2,3}$ Yanzhao Wei, ${ }^{4}$ Minggong Guo $\mathbb{D}^{5}{ }^{5}$ and Yanzhi $\mathrm{Li}^{5}$ \\ ${ }^{1}$ School of Emergency Management, Henan Polytechnic University, Jiaozuo 454000, Henan, China \\ ${ }^{2}$ State Key Laboratory Cultivation Base for Gas Geology and Gas Control, Henan Polytechnic University, Jiaozuo 454000, Henan, \\ China \\ ${ }^{3}$ The Collaborative Innovation Center of Coal Safety Production of Henan, Henan Polytechnic University, Jiaozuo 454000, \\ Henan, China \\ ${ }^{4}$ College of Safety Science and Engineering, Henan Polytechnic University, Jiaozuo 454000, Henan, China \\ ${ }^{5}$ The No. 8 Mine of Pingdingshan Tianan Coal Mining Co., LTD, Pingdingshan 467000, Henan, China
}

Correspondence should be addressed to Minggong Guo; gmg666@163.com

Received 12 January 2021; Revised 23 February 2021; Accepted 14 March 2021; Published 23 March 2021

Academic Editor: Gong-Da Wang

Copyright (c) 2021 Wei Wang et al. This is an open access article distributed under the Creative Commons Attribution License, which permits unrestricted use, distribution, and reproduction in any medium, provided the original work is properly cited.

The current study aims to analyze the principles of integrated technology of explosion to tackle the problems of coal seam high gas content and pressure, developed faults, complex structure, low coal seam permeability, and high outburst risk. Based on this, we found through numerical simulation that as the inclination of the coal seam increases, the risk of coal and gas outburst increases during the tunneling process. Therefore, it is necessary to take measures to reduce the risk of coal and gas outburst. We conducted field engineering experiments. Our results show that the synergistic antireflection technology of hydraulic fracturing and deephole presplitting blasting has a significant antireflection effect in low-permeability coal seams. After implementing this technology, the distribution of coal moisture content was relatively uniform and improved the influence range of direction and tendency. Following 52 days of extraction, the average extraction concentration was 2.9 times that of the coal seam gas extraction concentration under the original technology. The average scalar volume of single hole gas extraction was increased by 7.7 times. Through field tests, the purpose of pressure relief and permeability enhancement in low-permeability coal seams was achieved. Moreover, the effect of gas drainage and treatment in low-permeability coal seams was improved, and the applicability, effectiveness, and safety of underground hydraulic fracturing and antireflection technology in low-permeability coal seams were verified. The new technique is promising for preventing and controlling gas hazards in the future.

\section{Introduction}

Gas is the main factor restricting coal mining safety. Coalgas outburst is a complex dynamic phenomenon in underground coal mines, which has occurred frequently over the past 150 years. The coal-gas outburst process includes four stages: outburst occurrence, rapid development, deceleration development, and outburst termination [1]. The coal mines enter the stage of deep mining in China [2]. The prevention of coal and gas outbursts is facing unprecedented challenges with an average mining depth of $650 \mathrm{~m}$ and rapid extension to the deep at a rate of $10 \sim 25 \mathrm{~m}$ per year and the increase of coal seam mining depth [3]. Most of the dynamic disasters occurred in areas deeper than $700 \mathrm{~m}$ [4]. Currently, the main tools to enhance coal seam permeability and strengthen gas drainage mainly include hydraulic fracturing, hydraulic punching, hydraulic slitting, loose blasting, and deep-hole presplitting blasting. 
Recently, many scholars have conducted extensive and indepth research on deep-hole presplitting blasting, the mechanism of hydraulic fracturing technology, and field applications and achieved promising results. They used numerical simulation, analyzed the expansion law of coal blasting lines, and determined the spacing of drainage holes. The coal body firmness coefficient and coal seam gas pressure positively affect the penetration enhancement of coal seam deep-hole blasting. Moreover, high ground stress severely inhibits the coal seam blasting cracks and studies the coal seam's plot coefficient $f<1$ and the impact of time on the antireflection effect $[5,6]$. To study the influence of the distance from a control hole to a blasting hole on fractures' evolution laws, finite element software LS-DYNA is used to perform presplitting blasting of the deep hole for different distance coal. It is concluded that, under the effect of tensile stress superposition from stress wave and free surface reflection effect, $3 \mathrm{~m}$ blasting hole around the control hole can form 10 to 13 main cracks [7].

The permeability improvement method uses presplitting and blasting technology and multiple boreholes to improve the permeability of the soft coal seam, which is achieved by optimizing the inseam distribution of generated fractures through multiple control boreholes. The permeability improved by presplitting and blasting with deep boreholes is 2.5 times higher than the original coal seam [8]. Previous study reports the mechanism of deep-hole presplitting blasting, which strengthened gas drainage in coal seams with low permeability. Hydraulic fracturing technology is widely used in the development of low-permeability oil and gas fields [9, 10].

In 1965, the Fushun Branch of the Central Coal Research Institute introduced the technology for the coal seam penetration enhancement. Coal seam pulsating hydraulic fracturing pressure can provide relief and increase the permeability enhancement technology based on ordinary hydraulic fracturing and pulse water injection technology $[11,12]$. Hydraulic fracturing has a significant effect and mechanism for improving coal and rock permeability and enhancing gas drainage capacity [13]. The coal seam pulse hydraulic fracturing technology was studied and compared with general methods of hydraulic fracturing, the results of industrial experiments show that pulse hydraulic fracturing generates a better effect of pressure relieving and permeability improving [14]. Permeability improvement technology of directional hydraulic penetration by guided groove was described and studied in detail, and they found that the efficiency of gas drainage has been significantly improved [15]. Variable frequency, a new pattern of pulse hydraulic fracturing, is presented for improving permeability in coal seam, and they found that it is better to select the sequence of low frequency at first and then high frequency. Which hydraulic fracturing for the bottom-draining roadway was investigated [16]. They develop the fractal calculation models of the fracture robustness and the filtration coefficient of fracturing fluid under hydraulic fracturing [17]. The evolution laws of permeability and gas pressure during hydraulic fracturing in the underground gas drainage were studied and several influence factors were analyzed by accomplishing a series of simulations. Gas drainage can effectively be enhanced when the hydraulic fracturing induced damage zone is a breakthrough at the drainage hole. After the coal seam is effectively fractured, the gas flux has a decline-incline-decline tendency with increasing drainage time. The breakthrough time of the damage zone increases linearly with coal seam elastic modulus, increases exponentially with vertical stress and borehole spacing, and decreases exponentially with injecting pressure [18]. When the fracturing time increases, the coal seam's porosity gradually increases and finally reaches a fixed value [19].

Recently, to solve the problems of a long time and high cost of gas drainage for common coal seam antireflection measures, numerous studies report the coupled antireflection technology of hydraulic and blasting and found that the coupling technology has better coal seam permeability compared with the original technology. The coupling technology greatly improved in recent years. For the gas drainage effect of a coal seam with high gas content and low permeability, hydraulic-controlled blasting of a deep hole was conducted to provide pressure relief and increase a coal seam's permeability. Moreover, they found that the technology can connect boreholes through fractures, effectively discharge coal seam gas and release gas pressure, significantly improve the coal seam's permeability, and reduce gas drainage time [20]. Hydraulic fracturing and deep-hole presplitting blasting synergistic antireflection technology improve the permeability of coal seams more efficiently than the hydraulic fracturing technology, deep-hole presplitting blasting antireflection technology, and ordinary drainage technology [21]. The increasing water content of coal can significantly reduce the risk of gas outbursts. The technology of promoting coal seam infusion by blasting has been proposed to increase the water injection volume. The blasting promotes equilibrium distribution in the stress field and generates new fractures, promoting the water injection [22]. In an attempt to increase the permeability and high-gas coal seams and improve gas utilization and drainage efficiency, a previous study proposed the hydraulic fracturing deep-hole presplitting blasting composite antipermeability technology and analyzed the hydraulic fracturing deep-hole presplitting [23]. The blasting cracking mechanism of the composite antireflection of split blasting was established, as well as the equation of the stress intensity factor of the crack and the equation of the secondary crack propagation radius under detonation gas [24].

To solve the problems of coal seam gas content, high gas pressure, developed faults, complex structure, poor coal seam permeability, and high outburst risk in the $8^{\text {th }}$ Mine of Pingdingshan Coal Mining Group, the method of combining theoretical analysis and field engineering tests were was for coupling technology of deep-hole presplitting blasting and hydraulic fracturing.

\section{Numerical Simulation of the Influence of Coal Seam Dip Angle Change on Outburst Hazard of Coal Heading Head}

2.1. Working Face Profile. The buried depth of 15-15060 face working in the 8th Mine of Pingdingshan Coal Mining Group is $580 \sim 636 \mathrm{~m}$, the coal seam thickness is relatively stable, the coal thickness is usually $2.9 \sim 3.8 \mathrm{~m}$ with an average of $3.3 \mathrm{~m}$, the coal seam inclination is $10 \sim 18^{\circ}$, the average is $12^{\circ}$, and the coal seam is semibright-type coking coal. The 
lower part is the $16^{\text {th }}$ coal, the thickness of the coal seam is 1.5 to $2.3 \mathrm{~m}$, the average thickness is $1.9 \mathrm{~m}$, and the interlayer spacing is $7.9 \mathrm{~m}$. The $15^{\text {th }}$ coal seam's direct roof is dark gray thick layered sandy mudstone with clear bedding, and the basic top is light gray medium-fine-grained sandstone. The coal seam's direct bottom is mudstone, containing plant root fossils, which is easy to expand when exposed to water, and the basic bottom is a thin layer gray shape sandy mudstone. The gas pressure is $1.89 \mathrm{MPa}$, and the gas content is $13.7 \mathrm{~m}^{3}$ / $t$. It is classified according to the outburst hazard level and belongs to the outburst hazard working face.

2.2. Model Building. During underground coal road excavation, the excavation work destroys the original equilibrium state of the surrounding coal and rock, resulting in a stress concentration area, and the roadway wall area near the heading head also has a significant numerical displacement; therefore, the heading head is often more prone to outburst accidents. The stress concentration area is generated during the roadway excavation process. It is easy to understand the possibility of outburst hazards around coal roadways under different coal seam inclination angles and study the effect of coal seam inclination on outburst accidents by a comparative analysis of the maximum stress and the area of the stress concentration area under different coal seam inclination angles. The FLAC3D simulation software is used to establish a numerical simulation model of coal and rock layers during tunneling in underground coal mines. Based on the different inclination angles of coal seams, a total of 6 models have been established. The inclination angles of coal seams are $0^{\circ}, 5^{\circ}, 10^{\circ}, 15^{\circ}, 20^{\circ}$, and $25^{\circ}$. The size of the model is $80 \mathrm{~m} \times 80 \mathrm{~m} \times 80 \mathrm{~m}$, and it is divided into three layers. The upper layer is the coal seam's top rock layer, the middle layer is the coal seam, and the lower layer is the bottom rock layer of the coal seam. The coal seam is $3.3 \mathrm{~m}$ thick, and the roadway is dug in the middle of the coal seam. The roadway is $5 \mathrm{~m}$ wide, and the middle part of the roadway is $2.2 \mathrm{~m}$ high. The top surface is directly excavated to the rock layer. The stress boundary is set on the top surface of the rock layer at the top of the model, and the displacement boundary is set on the remaining 5 surfaces of the model, as shown in Figure 1.

According to the measured in situ stress value of the mine, the model's in situ stress is set to $20 \mathrm{MP}$, and the mechanical parameters of coal and rock are shown in Table 1.

For simulation, the length of the model is $80 \mathrm{~m}$, and the roadway is driven $40 \mathrm{~m}$ in the coal seam. Among them, the first 25 meters are located at the edge of the model and exhibit a boundary effect, which is not suitable for detailed analysis. Therefore, rapid excavation is adopted, and only 3 calculations were performed. The next 15 meters are in the middle of the model, with a high grid density and high accuracy. The calculation was performed after every one meter of excavation.

\subsection{Influence of Coal Seam Dip Angle Change on Outburst} Danger of Driving Head. The stress cloud diagram on the section of the heading head is drawn through the software, and a three-dimensional stress diagram is constructed, as shown in Figures 2 and 3.

We found that the stress distribution of the head section shows a distribution law of double peaks and deep valleys during stress map analyses. The possible reason is that the coal in the tunnel is excavated and removed, the stress value in this area is 0 , and it forms a deep valley on the three-dimensional stress map. Observing the coal seams on both sides of the driving roadway, when the distance from the driving roadway increases, the coal seam stress gradually increases and reaches a maximum value at a certain distance from the driving roadway. Two towering peaks are formed on the three-dimensional stress map because the tunneling destroys the coal seam's original stress balance, causing the stress around the roadway to accumulate gradually. When the distance from the excavation roadway exceeds the stress peak position, the coal seam stress gradually decreases until it reaches a stable value. This is because the coal seams that are far away from the roadway are less affected by the roadway. Observing the rock formation area around the roadway, it can be found that, except for the area close to the excavation roadway due to the influence of tunneling, the stress value of the rock formation is maintained in a relatively stable area, which appears as a plain on the three-dimensional stress map. The possible reason is that the rock layer is harder, and the stress state is not easily affected by roadway driving.

We found that the stress distribution of the head section shows a distribution law of double peaks and deep valleys by analyzing the stress diagram. As the coal in the tunnel is excavated and removed, the stress value in this area is 0 , forming a deep valley on the three-dimensional stress map. Observing the coal seams on both sides of the driving roadway, with different coal seam inclination angles, the stress distribution of the head section still shows similar distribution characteristics, indicating a state of double peaks with deep valleys, rotating around the driving roadway, and the double peaks are often in the coal seam. These findings indicate that no matter how the inclination angle of the coal seam changes, the outburst around the roadway still mainly occurs in the coal seam, and the outburst of the rock layer around the roadway is less dangerous.

The increase of the inclination of the coal seam can progressively improve the maximum stress on the section of the heading head from $-2.9865 \times 107$ to $-3.1265 \times 107$, with an increase of about $4.7 \%$. For every $1^{\circ}$ increase in the average coal seam inclination, the maximum stress value increased by $0.16 \%$. Therefore, considering the maximum stress, when the inclination of the coal seam increases, the danger of outbursts around the roadway will also be increased.

\subsection{Conclusions Reached through FLAC3D Simulation}

(1) No matter how the inclination angle of the coal seam changes, the outburst hazard around the roadway mainly occurs in the coal seam during the driving process of the coal roadway, and the outburst in the rock layer is less dangerous.

(2) When the inclination of the coal seam increases, the probability of outburst around the heading head will also be increased.

(3) When the coal seam's inclination angle increases, the areas with a higher probability of outbursts around the roadway will gradually gather in the coal seam above the roadway. 


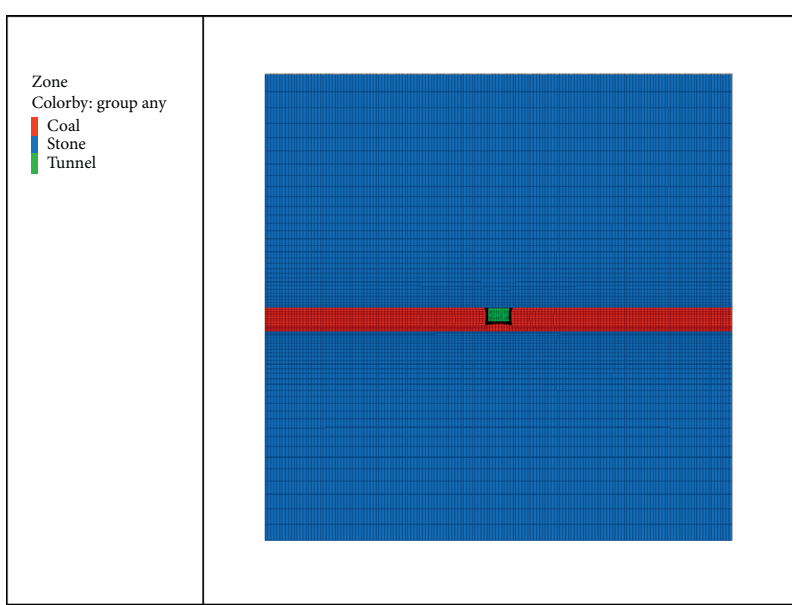

(a)

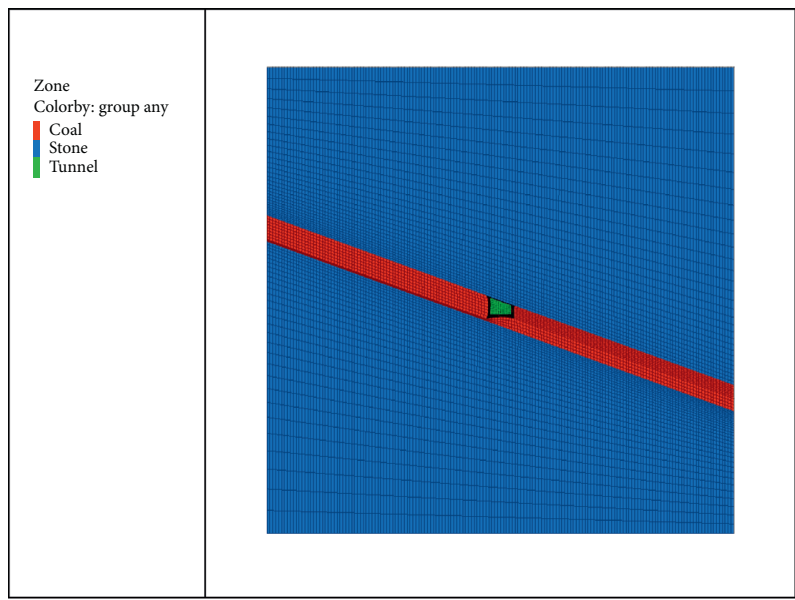

(c)

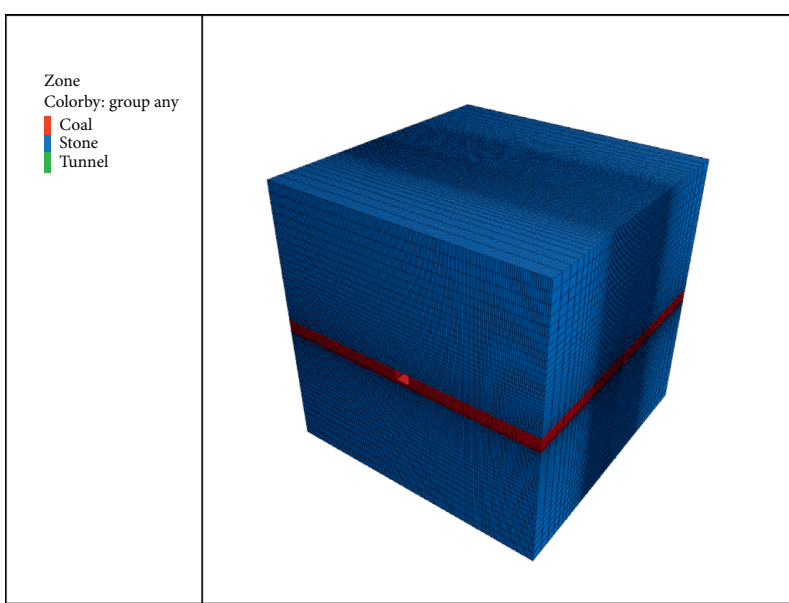

(b)

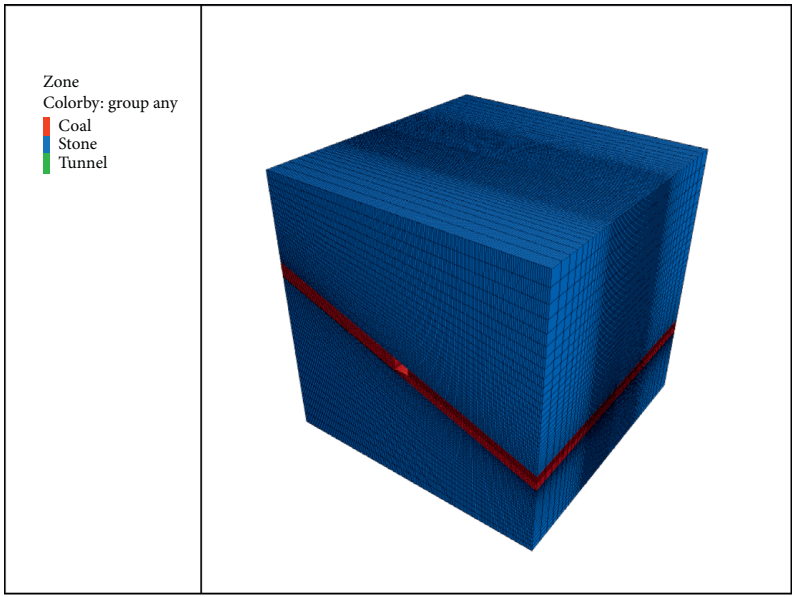

(d)

FIgURE 1: Example diagram of numerical simulation model of coal road driving with $0^{\circ}$ and $20^{\circ}$ dip angle coal seams.

TABLE 1: Mechanical parameters of coal and rock formations.

\begin{tabular}{lccccc}
\hline Classification & Elastic modulus $(\mathrm{GPa})$ & Poisson's ratio & Internal friction angle $\left({ }^{\circ}\right)$ & Cohesion $(\mathrm{MPa})$ & Density $\left(\mathrm{kg} / \mathrm{m}^{3}\right)$ \\
\hline Coal & 2 & 0.35 & 20 & 0.3 & 1350 \\
Rock & 10 & 0.3 & 25 & 2 & 2500 \\
\hline
\end{tabular}

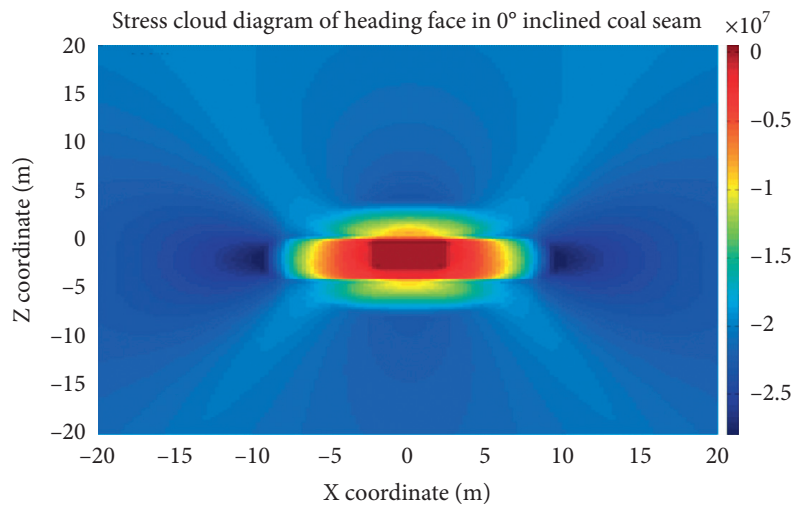

(a)

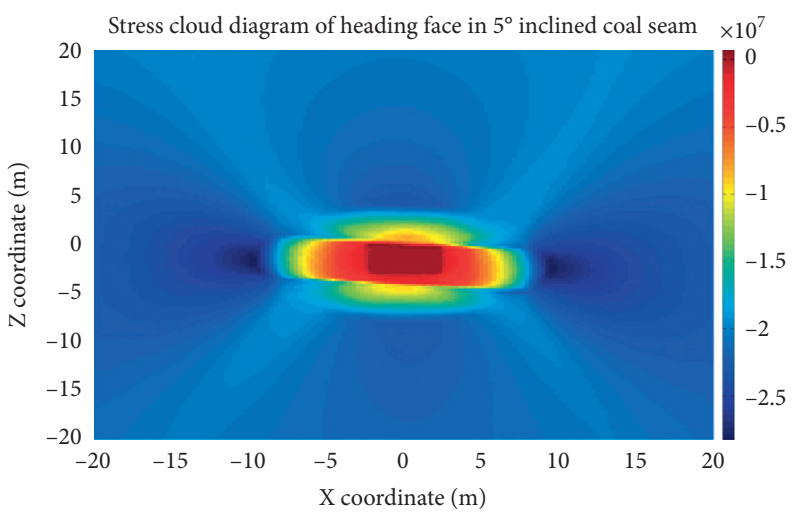

(b)

FIgure 2: Continued. 


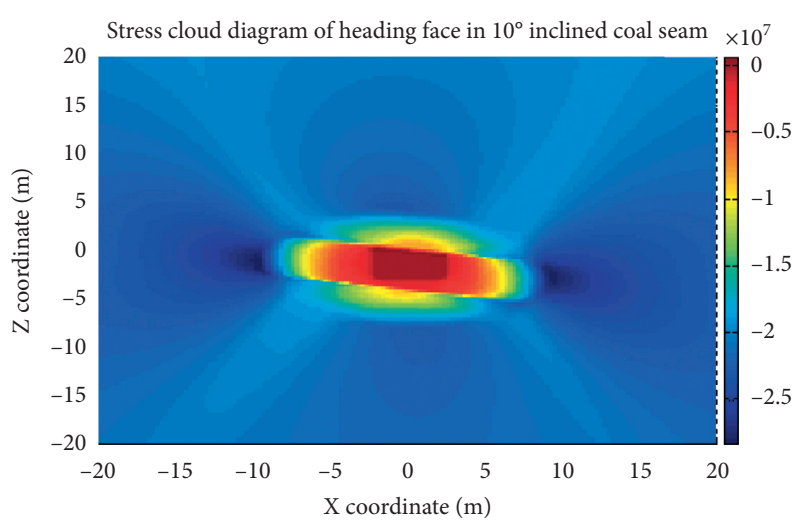

(c)

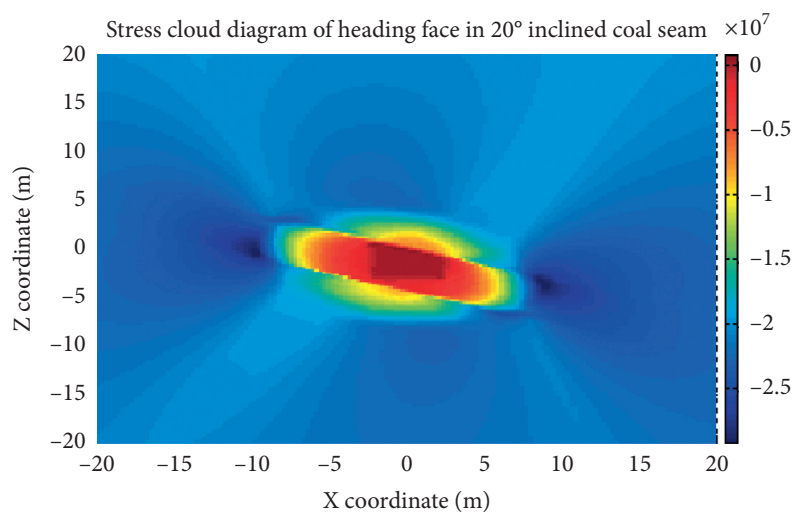

(e)

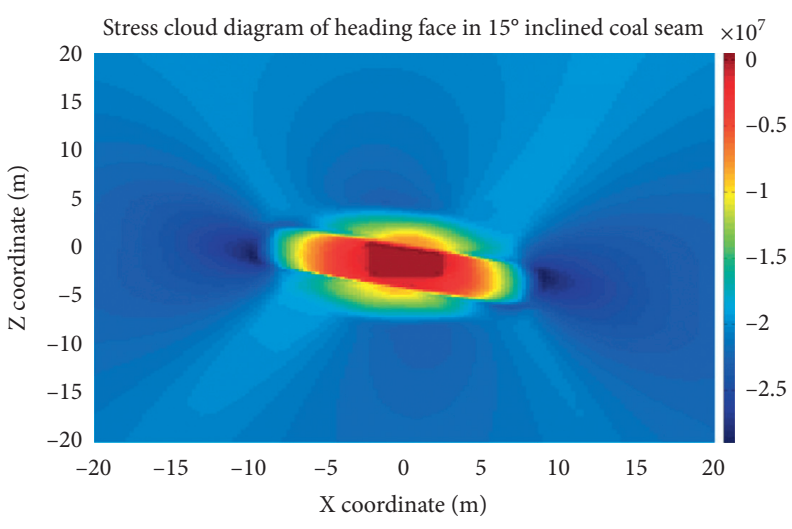

(d)

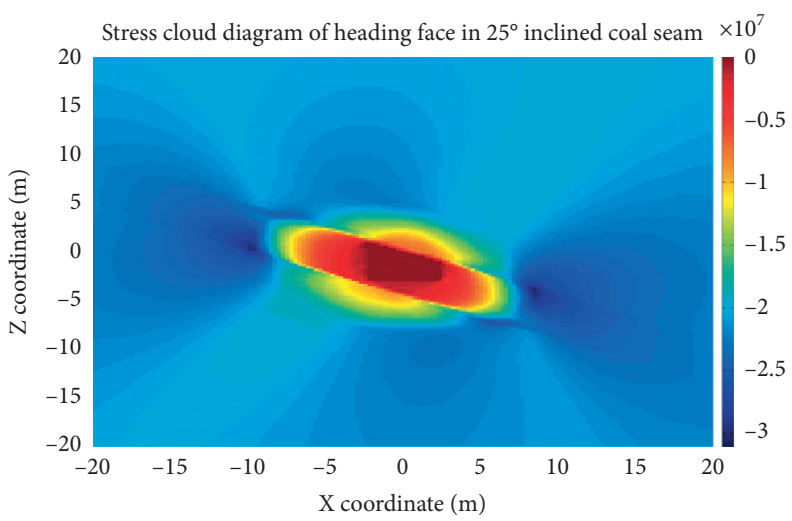

(f)

Figure 2: Plane cloud diagram of the section stress of the roadway heading head under each coal seam dip.

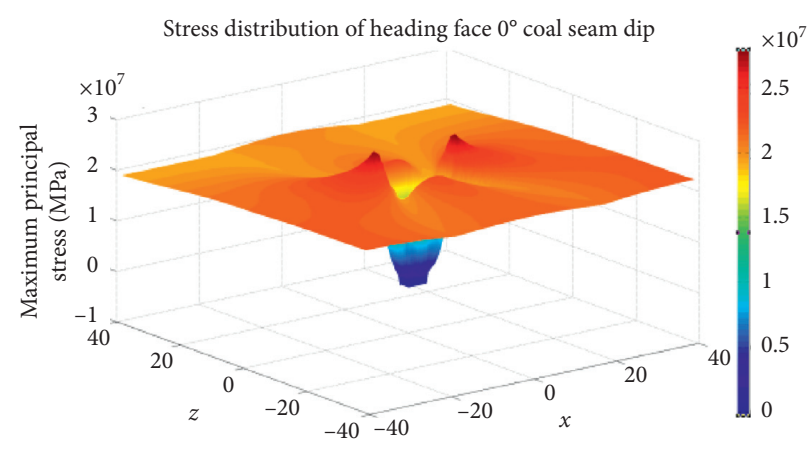

(a)

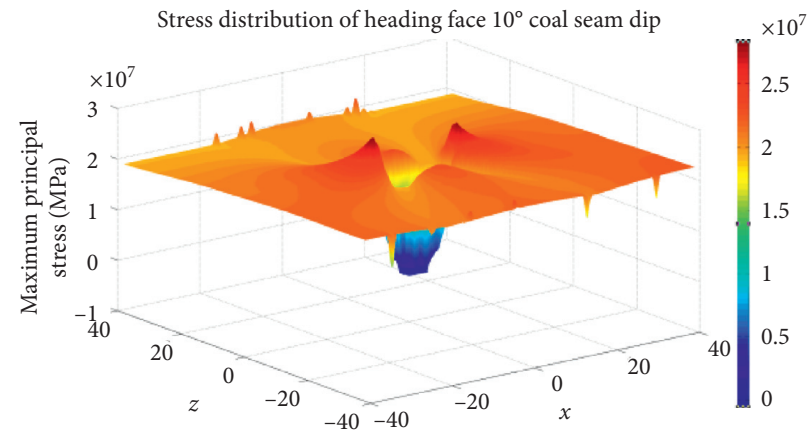

(c)

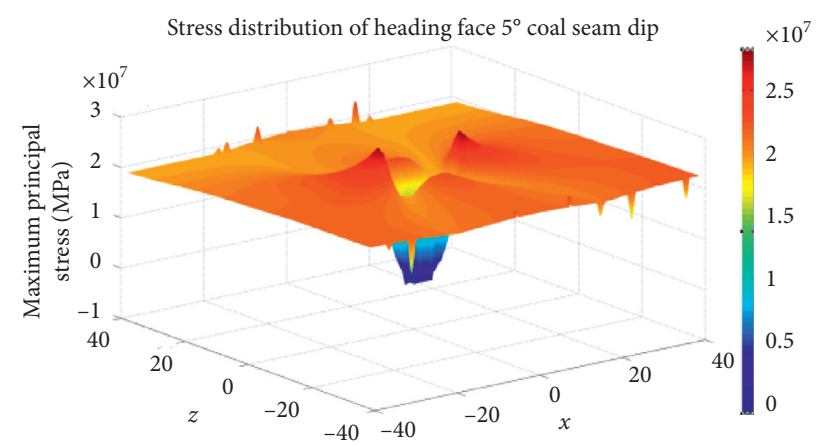

(b)

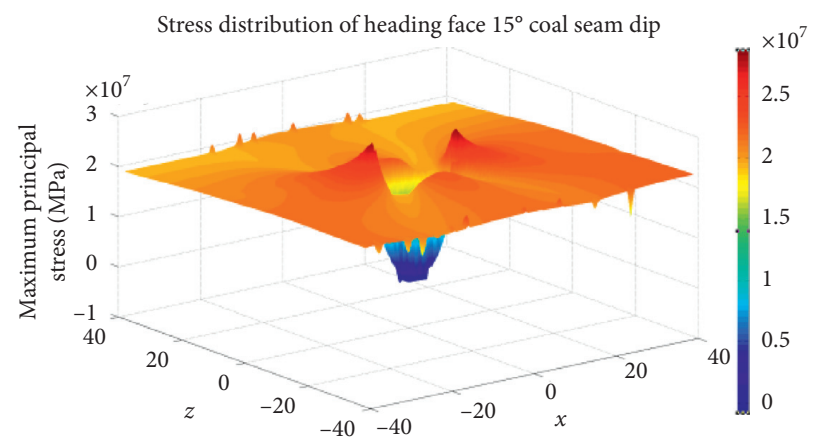

(d)

FIgURe 3: Continued. 


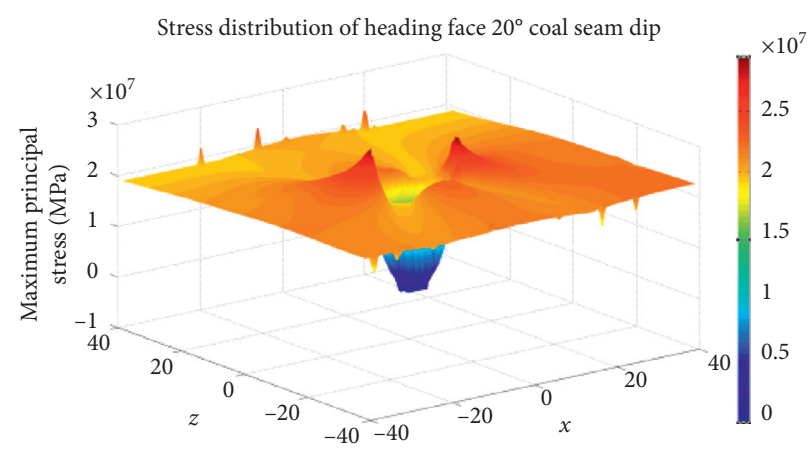

(e)

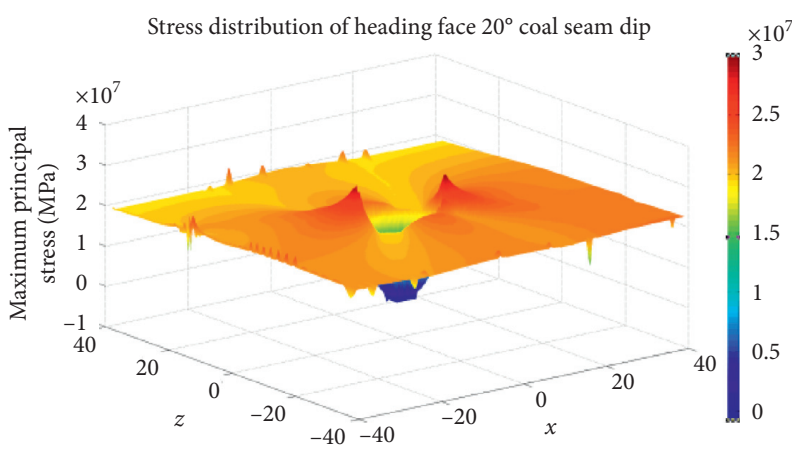

(f)

FIgURE 3: Three-dimensional diagram of the section stress of the roadway heading head under each coal seam dip.

From the above conclusions, it is established that, during coal roadway excavation, the roadway's outburst danger mainly occurs in the coal seam. Therefore, in these positions, gas outburst enhancement and elimination technology must be adopted to ensure coal mine production safety. These technologies include hydraulic enhancement, mining protective layer, loose blasting, and deep-hole presplitting blasting. These drainage technologies have long drainage cycles in outburst coal seams with low air permeability and a small impact area, increasing the time and cost of safe investment in the mining. Because the coal seam has a certain inclination angle, numerical simulation can show that as the inclination angle increases, the risk of coal seam outburst also increases. Not only is the No. 8 Mine of Pingdingshan Coal Mining buried deep but also it has a certain inclination angle, and the effect of conventional gas penetration enhancement measures is average. Therefore, it is necessary to adopt a more effective method to increase the permeability of coal seam gas.

This paper uses the blast-injection integrated antireflection technology for research. The blasting and injection integrated antireflection technology can directly perform hydraulic fracturing after deep-hole presplitting blasting to achieve the comprehensive purpose of strengthening gas drainage at the working face and improve coal seam permeability.

\section{Field Engineering Test of Blast-Injection Integrated Antireflection Technology}

The test site is located in the bottom extraction roadway of 15-15160 machine road in the No. 8 Mine of Pingdingshan Coal Mining Group Co., Ltd. The pressure holding hole and the blasting-injection hole are arranged, and the distance between the two holes is $100 \mathrm{~m}$. As shown in Figure 4, the pressureholding hole is arranged at an elevation angle of $58^{\circ}$ at the bottom of the suction roadway of 15-15060 machine roadway, which is perpendicular to the middle line of the roadway side. As shown in Figure 5, the opening position of the blasting hole is located at the lower side of the roadway at an elevation angle of $74^{\circ}$, passing through the center of the roadway, and the drill hole passes through the 15 th coal seam's $0.5 \mathrm{~m}$ roof.
As shown in Figure 6, we constructed 10 drilling holes in each of the four horizontal and vertical directions around the pressure-holding hole, for a total of 40 observation holes. The distances between the bottom of the 10 observation holes in each direction and the pressure-holding hole are $3 \mathrm{~m}, 6 \mathrm{~m}, 9 \mathrm{~m}, 12 \mathrm{~m}, 15 \mathrm{~m}, 18 \mathrm{~m}, 21 \mathrm{~m}, 25 \mathrm{~m}, 30 \mathrm{~m}$, and $35 \mathrm{~m}$, respectively. The drilling of No. $20-$ No. 40 is perpendicular to the direction of the roadway. As shown in Figure 7, the drill moves to a fixed position when constructing a fracturing hole and changes the drilling angle to construct Nos. 21-40 holes.

As shown in Figure 8, the blast hole is constructed with 8 observation holes in each of the four horizontal and vertical directions, for a total of 32 observation holes. The distances between the 8 observation holes in each direction and the bottom of the blast hole are $3,6,9,12,15,18,21$, and $25 \mathrm{~m}$, respectively. The 41-56 holes are drilled parallel to the direction of the roadway. As shown in Figure 9, the 57-72 holes are drilled perpendicular to the direction of the roadway and arranged in two rows, the single number row is outside the roadway, the double number row is inside the roadway, and the two split holes are $0.5 \mathrm{~m}$ away from the blast hole.

\section{Test Effect Analysis}

4.1. Comparison of Blast-Injection Integrated Antireflection Technology and Conventional Hydraulic Fracturing Influence Radius. We take the upper, middle, and lower coal samples of the observation hole of the pressure holding hole and the blast-injection hole to measure the water content, as shown in Figure 10, and draw the relationship between the water content and the distance.

It can be seen from Figures 10(a) and 10(b) that, without blasting, the water content of the observation hole around the pressure holding hole is unevenly distributed, and the direction of the observation hole is within the range of $-18 \mathrm{~m} \sim 15 \mathrm{~m}$, and the inclined observation hole is within the range of $-21 \mathrm{~m} \sim 18 \mathrm{~m}$. The coal sample moisture content curve fluctuates abruptly, indicating that, during the fracturing process, the water body is not evenly distributed along with the trend or along the strike, and it is difficult to 


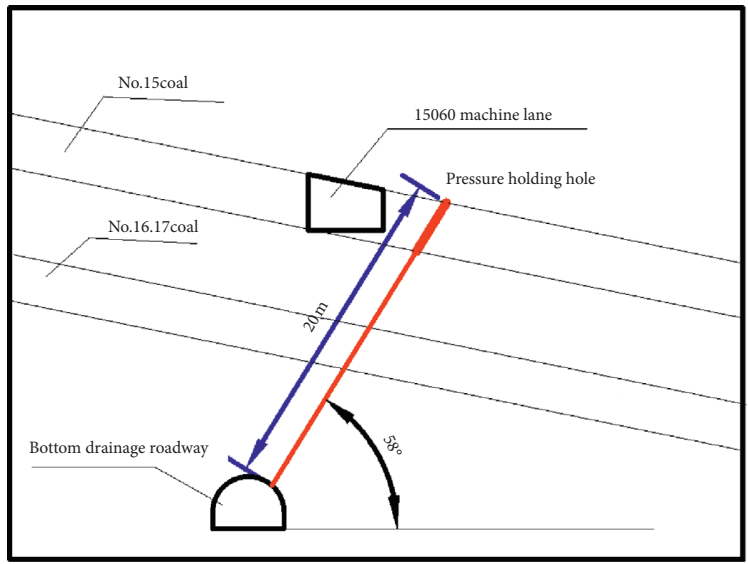

FIgURE 4: Sectional view of pressure holding hole.

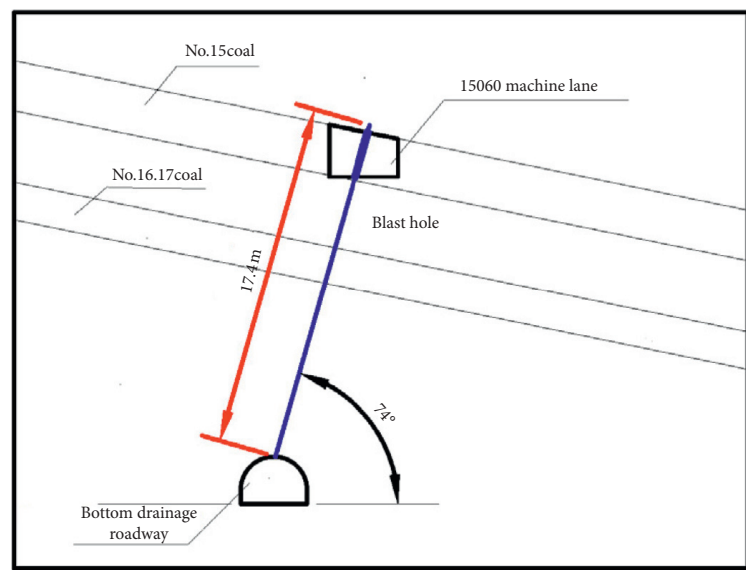

FIGURE 5: Sectional view of pressure blast hole.

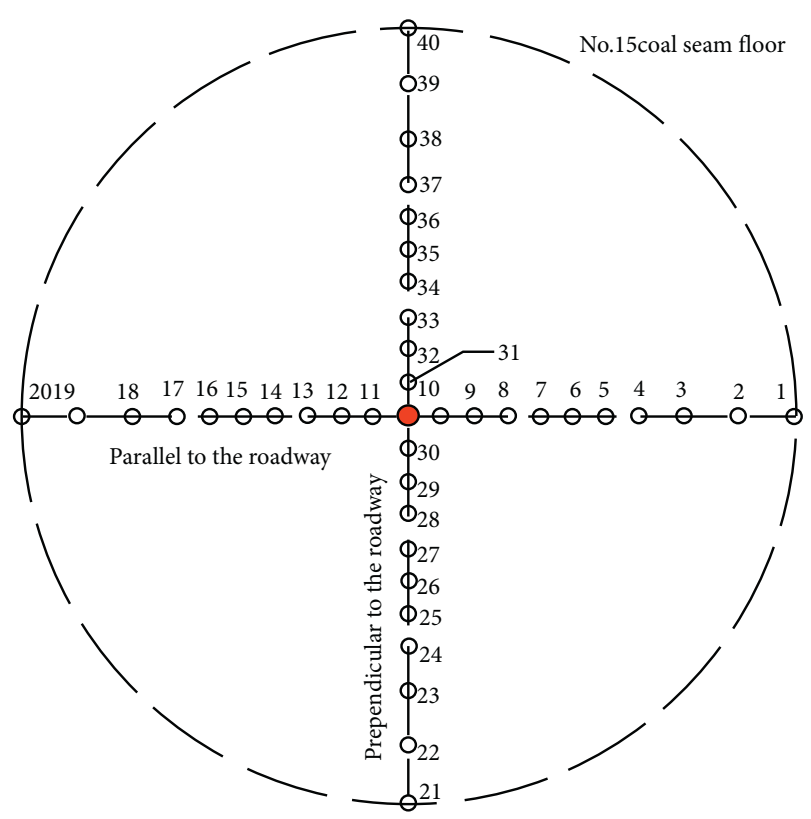

FIGURE 6: Schematic diagram of the observation hole number of the pressure holding hole.

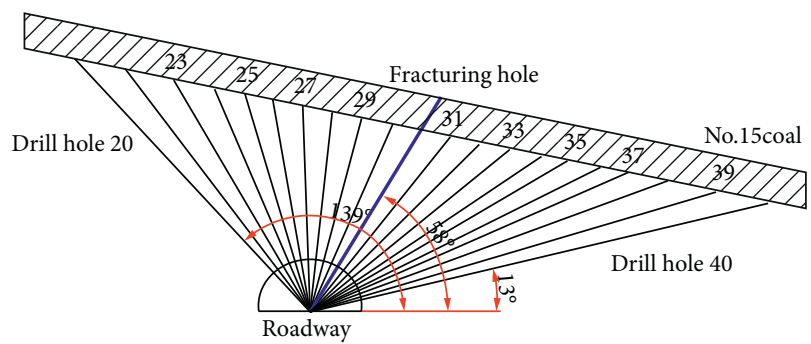

FIGURE 7: Sectional view of the observation hole number of the pressure holding hole.

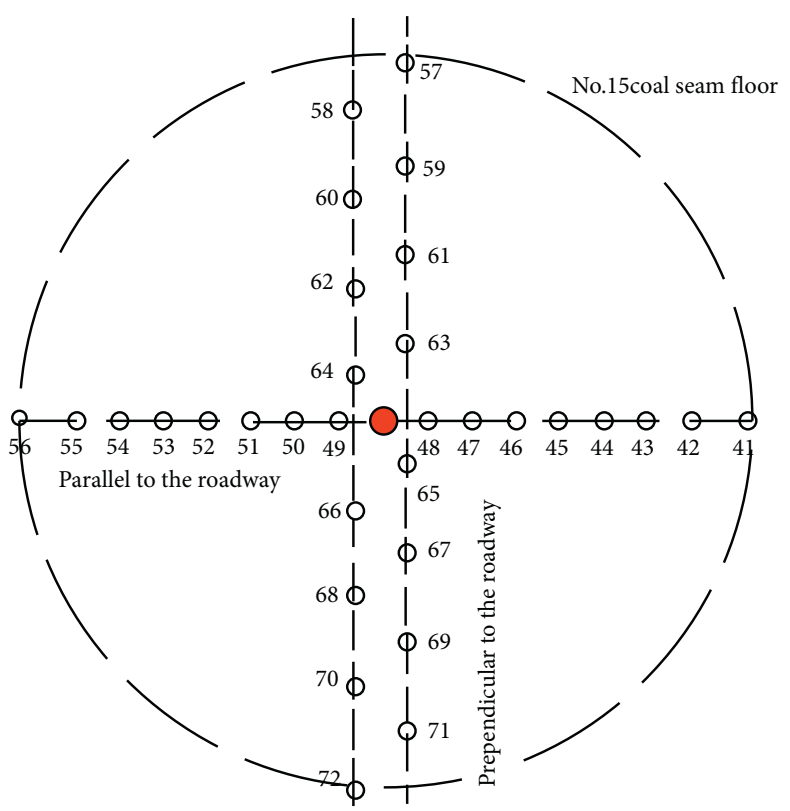

FIGURE 8: Schematic diagram of blast observation hole number.

determine the fracturing water's whereabouts. The coal body contains water at different sampling positions in the same observation hole and has a big difference in the rate. Generally, the lower coal sample has high water content, and the middle and upper parts have low water content. 


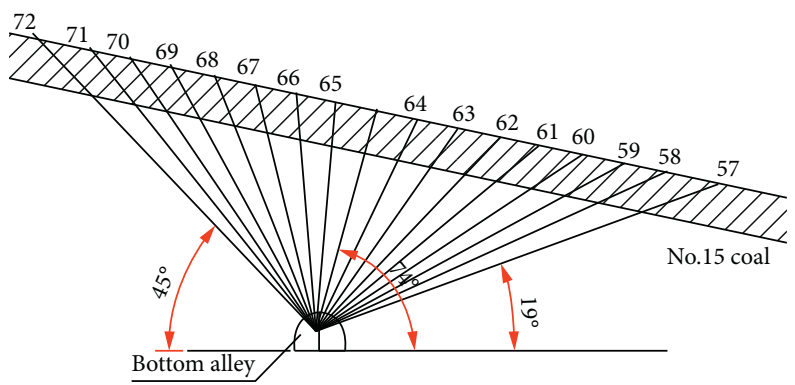

FIgURE 9: Sectional view of blast observation hole number.
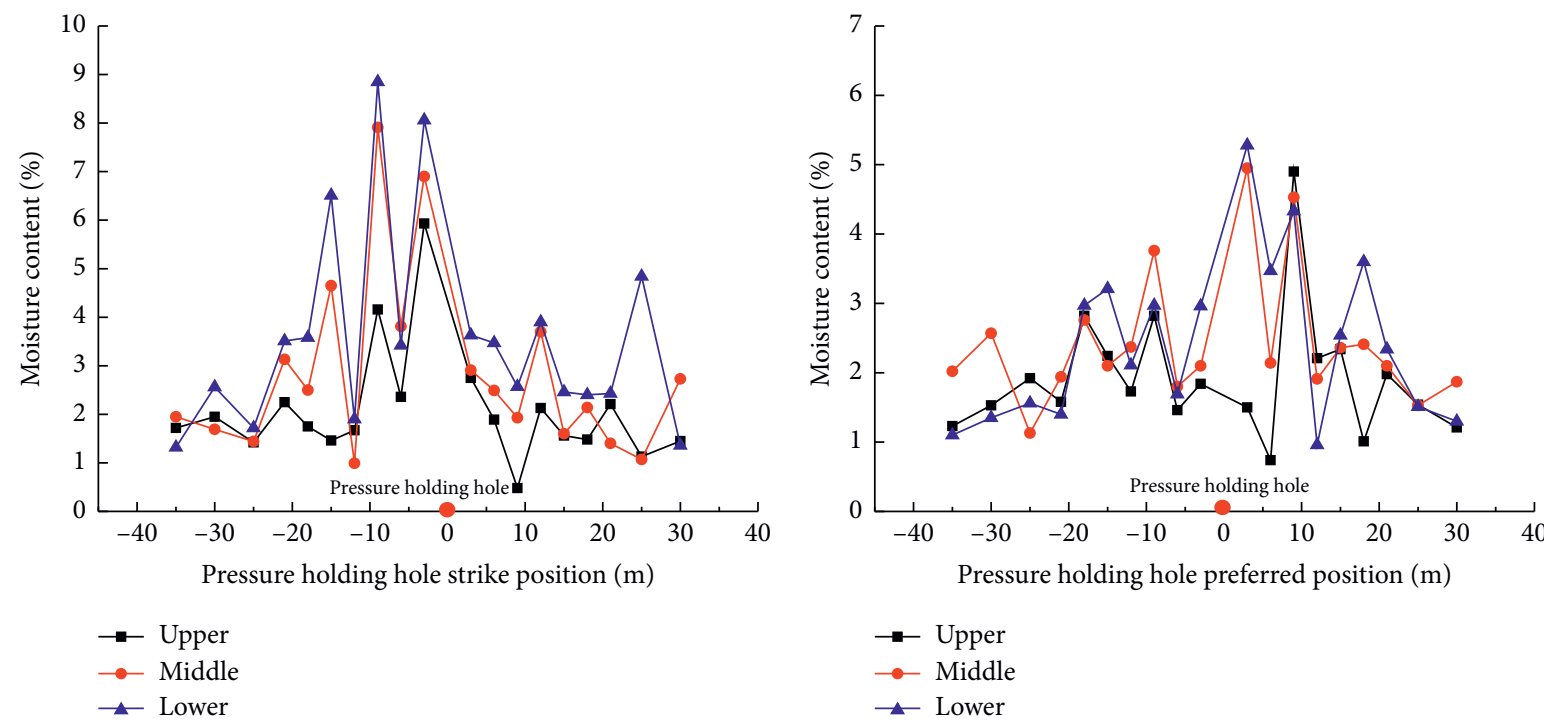

(a)

(b)
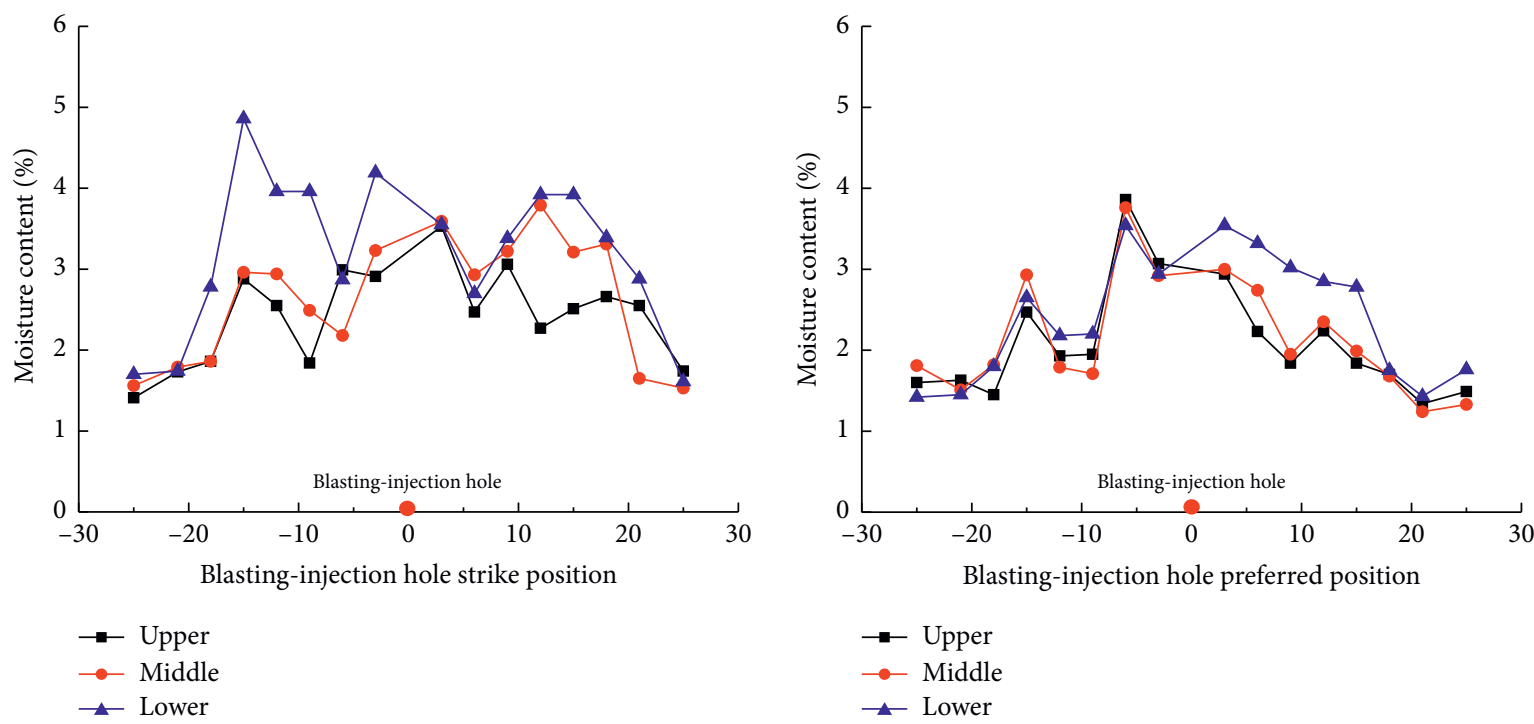

(c)

(d)

Figure 10: Water cut curve at different positions around the fracturing hole.

It can be seen from Figures 10 (c) and 10(d) that, after blasting, the water content curve of the coal body around the blasting hole is significantly smoother than the pressure holding hole. At different sampling positions of the same observation hole, the water content of the middle and upper coal bodies is higher, indicating good consistency. Except 


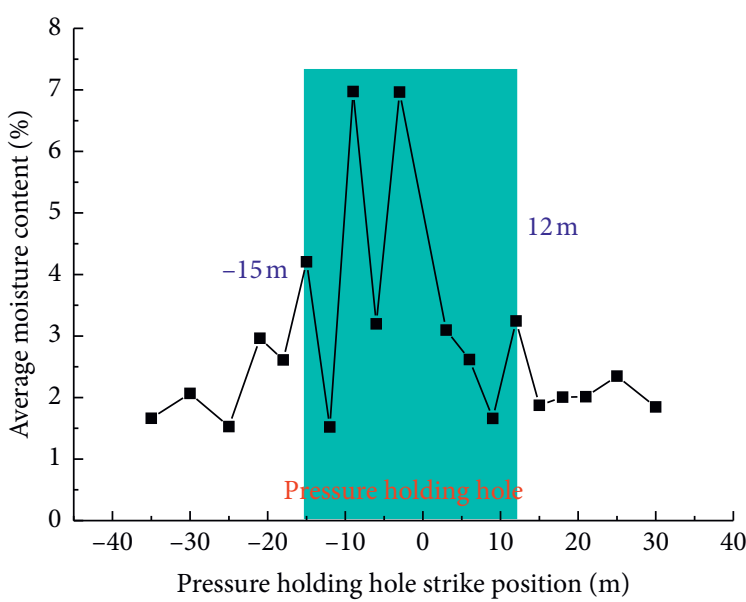

(a)

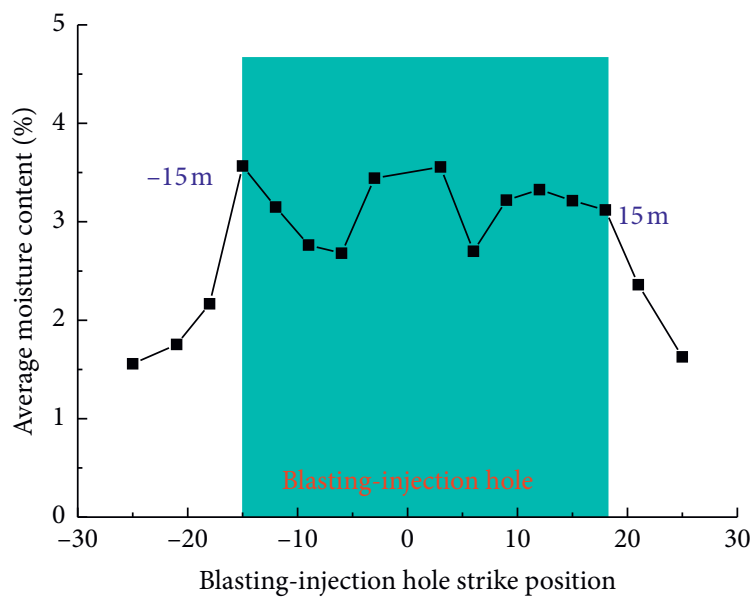

(c)

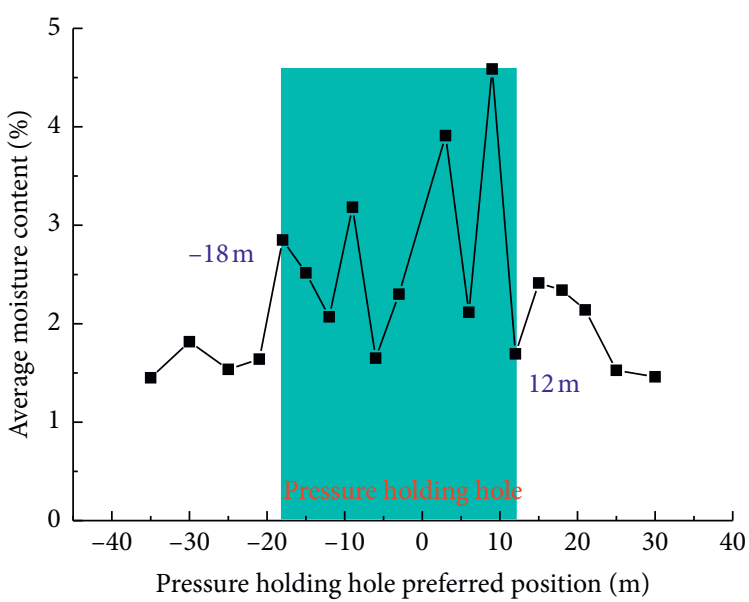

(b)

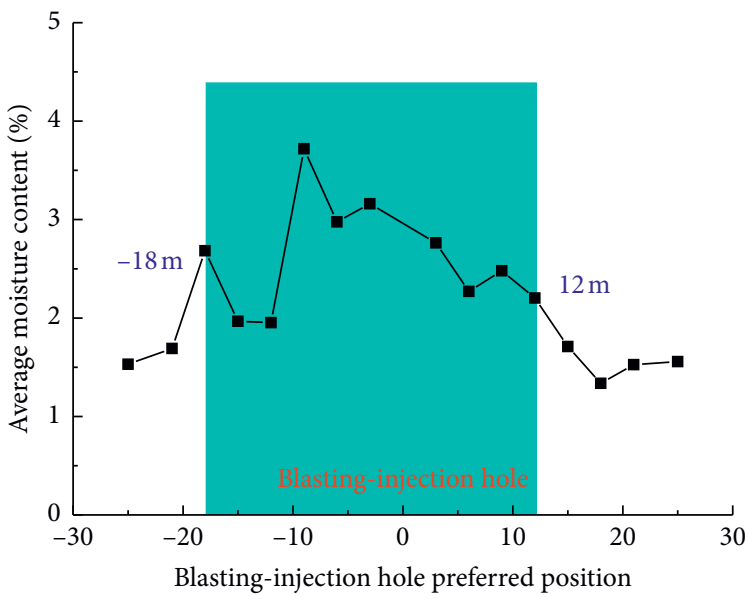

(d)

Figure 11: Relationship between test location and average moisture content.

that the water content of the lower coal body is generally higher with a range of $-18 \mathrm{~m} \sim-6 \mathrm{~m}$, the water contents of the upper, middle, and lower coal bodies are not much different in other test areas.

To determine the effective radius of the influence of the two fracturing methods, the relationship between the position of the observation hole and the average water content is plotted in Figure 11.

The pressure-holding hole direction and the water content tendency are unevenly distributed, as shown in Figures 11(a) and $11(\mathrm{~b})$. After going to $-15 \mathrm{~m}$ and $12 \mathrm{~m}$, the water content begins to decrease and gradually stabilizes. After the tendency to $-18 \mathrm{~m}$ and $12 \mathrm{~m}$, the water content gradually decreases and progressively stabilizes. In Figures 11(c) and 11(d), after blast hole strikes $-15 \mathrm{~m}$ and $15 \mathrm{~m}$, the moisture content gradually decreases and reaches the minimum value in the test range and tends to the area outside $-18 \mathrm{~m}$ and $12 \mathrm{~m}$, and the moisture content begins to decrease and achieves stability.

4.2. Comparison of Gas Drainage Effect between Blast-Injection Integrated Antireflection Technology and Conventional
Hydraulic Fracturing. After 52 days of on-site monitoring, the blast-injection integrated antireflection technology was compared with the original unfractured coal seam gas drainage data in the same drainage time to investigate the drainage effect before and after fracturing. We plot the gas concentration, average flow, and cumulative scalar into a curve.

It can be seen from Figures 12-14 that, after 52 days of drilling, the average concentration of gas in the blasting and fracturing area is $66.3 \%$, and the maximum concentration of a single group is $82 \%$. The average concentration is the same as that of coal seam gas extraction under the original technology, 2.9 times the concentration. The average gas scalar of a single drill hole is $0.024 \mathrm{~m}^{3} \cdot \mathrm{min}^{-1}$, and the maximum is $0.0031 \mathrm{~m}^{3} \cdot \mathrm{min}^{-1}$, which is an average increase of 7.7 times. For 52 days' draining, the blast-injection integrated synergistic antireflection technology is adopted. The scalar amount of gas drainage is $14003 \mathrm{~m}^{3}$, but when conventional hydraulic fracturing is used for gas drainage, the scalar amount of drainage is only $2310 \mathrm{~m}^{3}$, which increases nearly 6 times. 


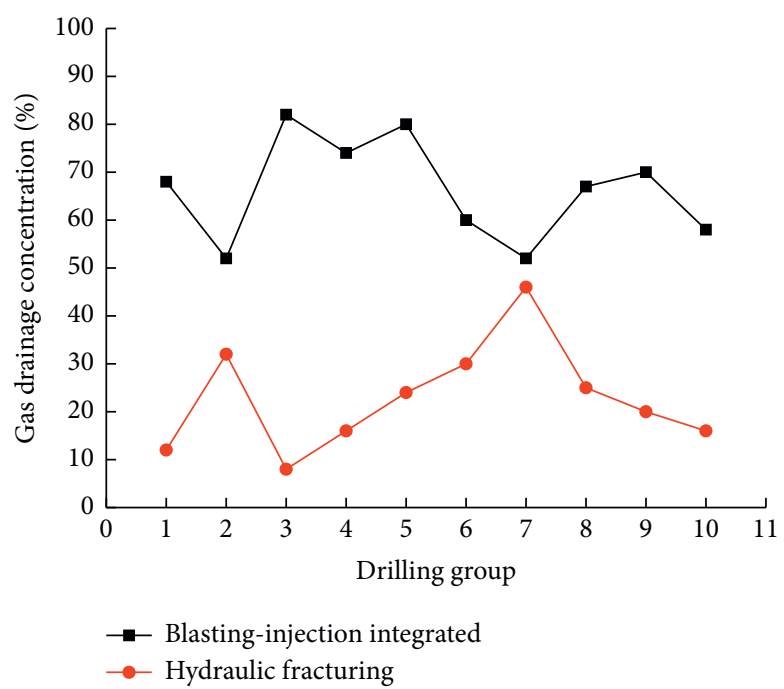

FiguRE 12: Comparison curve of gas drainage concentration before and after blasting-injection integrated antireflection technology.

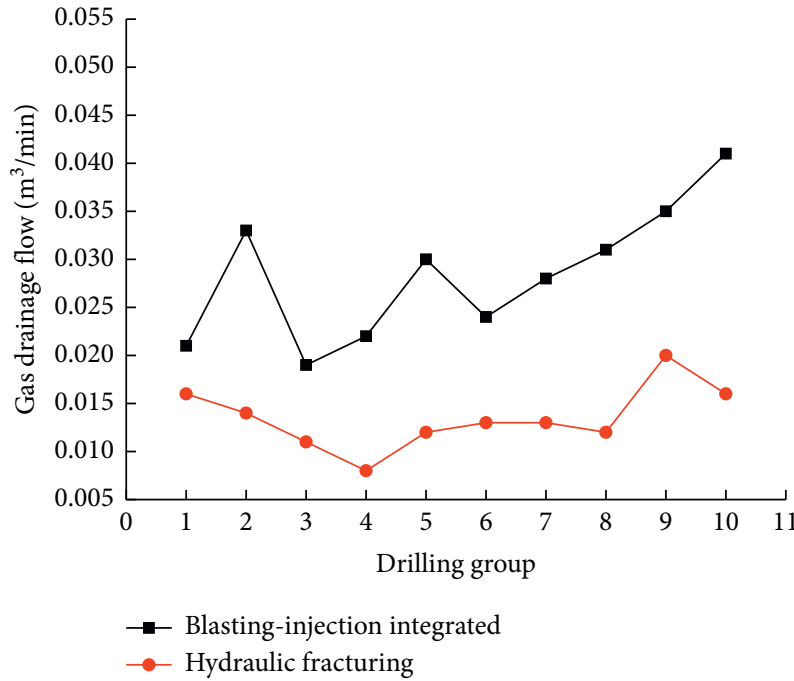

FIGURE 13: Comparison curve of gas drainage flow before and after blasting-injection integrated antireflection technology.

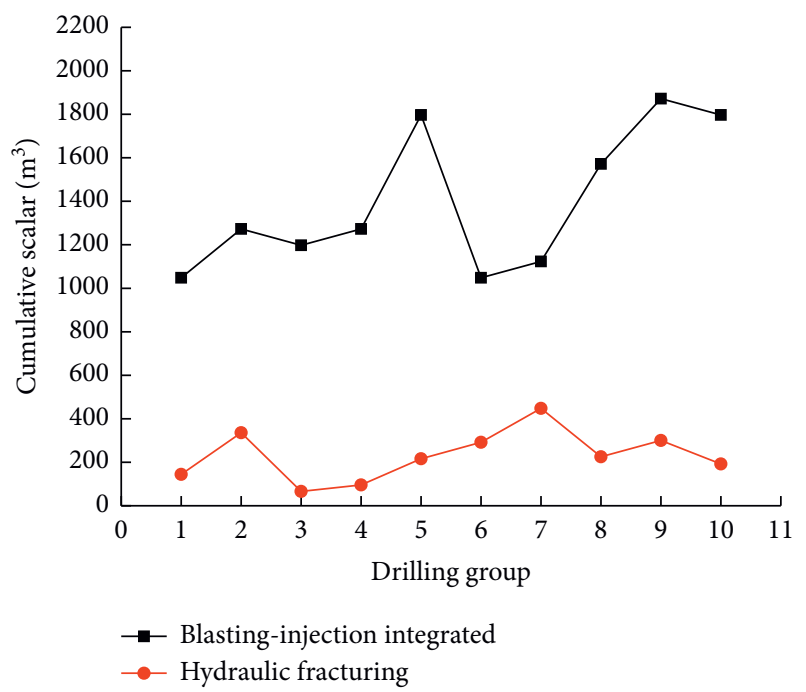

FIGURE 14: Comparison curve of cumulative scalar volume of gas drainage before and after blasting-injection integrated antireflection technology. 


\section{Conclusion}

We draw the following conclusions after analyzing the principle of blast-injection integrated antireflection technology and applying it in the No. 8 Coal Mine of Pingdingshan Coal Mine and comparing the effect of conventional hydraulic fracturing.

(1) Through numerical simulation, we found that it is established that, during coal roadway excavation, the roadway's outburst danger mainly occurs in the coal seam.

(2) The water content in coal bodies is severely rough near conventional fracturing and the peak and valley of water content alternately appear; however, blastinjection integrated technology is adopted to distribute water evenly around the fracturing hole. The blast-injection integrated technology has larger area of influence on the strike compared to conventional fracturing.

(3) After implementing blast-injection integrated technology, the gas drainage effect of outburst coal seams has low permeability. After 52 days of drainage, the average drainage concentration is 2.9 times that of the coal seam gas drainage concentration under the original technology. The average scalar was increased by 7.7 times.

(4) Through field tests, the purpose of pressure relief and permeability enhancement in low-permeability coal seams was achieved. Moreover, the effect of gas drainage and treatment in low-permeability coal seams was improved, and the applicability, effectiveness, and safety of underground hydraulic fracturing and antireflection technology in lowpermeability coal seams were verified.

This paper has conducted an in-depth analysis of the integrated technology of explosive injection and has achieved promising results. However, the experimental research is mainly conducted in the Ping coal mine area, and it still needs to be extended to other different mining areas to improve the construction technology. Different solidity coefficients of coal samples were studied separately to deal with different degrees of metamorphism, resulting in certain limitations in the experiment.

\section{Data Availability}

The data used to support the findings of this study are available from the corresponding author upon request.

\section{Conflicts of Interest}

The authors declare that there are no conflicts of interest regarding the publication of this paper.

\section{Acknowledgments}

This work was supported by the Key Science Research Project in Universities of Henan (19B620001 and
20A620004) and Key Science and Technology Program of Henan Province (202102310221).

\section{References}

[1] F. Du, K. Wang, X. Zhang, C. Xin, L. Shu, and G. Wang, "Experimental study of coal-gas outburst: insights from coalrock structure, gas pressure and adsorptivity," Natural Resources Research, vol. 29, no. 4, pp. 2481-2493, 2020.

[2] H. Lan, D. K. Chen, and D. B. Mao, "Current status of deep mining and disaster prevention in China," Coal Science and Technology, vol. 44, no. 1, pp. 39-46, 2016.

[3] M. C. He, H. Xie, P. S. Pneg, and Y. D. Jiang, "Study on rock mechanics in deep mininng engineering," Chinese Journal of Rock Mechanics and Engineering, vol. 16, pp. 2803-2813, 2005.

[4] K. Wang and F. Du, "Coal-gas compound dynamic disasters in China: a review," Process Safety and Environmental Protection, vol. 133, pp. 1-17, 2020.

[5] A. G. Su, Numerical Simulation on the Propagation Law of Presplitting Blasting Lines in Low Permeability Coal seams, Liaoning Technical University, Fuxin, China, 2013.

[6] B. Y. Zhao and H. D. Wang, "Feasibility of deep-hole blasting technology for outburst prevention and permeability enhancement in high-gas-content coal seams with low-permeability subjected to high geo-stresses," Explosion and Shock Waves, vol. 34, no. 2, pp. 145-152, 2014.

[7] C. Lv, J. Liu, and L. J. Guo, "Evolution laws of cracks under different hole pitch in deep hole pre-splitting blasting," Safety in Coal Mines, vol. 47, no. 11, pp. 65-68, 2016.

[8] C. G. Huang, Y. B. Zhang, J. F. He, Y. Luo, and Z. G. Sun, "Permeability improvements of an outburst-prone coal seam by means of presplitting and blasting with multiple deep boreholes," Energy Science \& Engineering, vol. 7, no. 5, pp. 2223-2236, 2019.

[9] S. Xiao, Z. Ge, L. Cheng, Z. Zhou, and J. Chen, "Gas migration mechanism and enrichment law under hydraulic fracturing in soft coal seams: a case study in songzao coalfield," Energy Sources Part A Recovery Utilization and Environmental Effects, pp. 1-15, 2019.

[10] J. Liu, Z. G. Liu, K. Gao, and W. Zhou, “Application of deep hole pre-splitting blasting to gas drainage at deep well and low permeability coal seam," Journal of Safety Science and Technolsogy, vol. 10, no. 5, pp. 148-153, 2014.

[11] Y. L. Li, Y. Liu, C. Wang, and Q. X. Wang, "Research and application of deep hole pre-splitting blasting technology for permeability enhancement in high gas and low permeability coal seam," Journal of Safety Science and Technology, vol. 16, no. 9, pp. 71-76, 2020.

[12] Z. W. Li, C. Zhai, Q. Bi, and Y. Y. Wen, "Pressure relief and permeability-increasing technology based on high pressure pulsating hydraulic fracturing and its application," Journal of Mining \& Safety Engineering, vol. 28, no. 3, pp. 452-455, 2011.

[13] Z. Yuan and Y. Shao, "Numerical modeling on hydraulic fracturing in coal-rock mass for enhancing gas drainage," Advances in Civil Engineering, vol. 2018, no. 8, 16 pages, Article ID 1485672, 2018.

[14] C. Zhai, X. Z. Li, and G. Q. Li, "Research and application of coal seam pulse hydraulic fracturing technology," Journal of China Coal Society, vol. 36, no. 12, pp. 1996-2001, 2011.

[15] Y. F. Wang and Y. Z. Li, "Technology and application of directional hydraulic penetration permeability improvement by guided groove," Journal of China Coal Society, vol. 37, no. 8, pp. 1326-1331, 2012. 
[16] L. Quangui, L. Baiquan, Z. Cheng et al., "Variable frequency of pulse hydraulic fracturing for improving permeability in coal seam," International Journal of Mining Ence and Technology, vol. 23, no. 6, pp. 847-853, 2013.

[17] F. Cai and Z. Z. Liu, "Simulation and experimental research on upward cross-seams hydraulic fracturing in deep and lowpermeability coal seam," Journal of China Coal Society, vol. 41, no. 1, pp. 113-119, 2016.

[18] X. Zhang, S. Zhang, Y. Yang, P. Zhang, and G. Wei, "Numerical simulation by hydraulic fracturing engineering based on fractal theory of fracture extending in the coal seam," Journal of Natural Gas Geoscience, vol. 1, no. 4, pp. 319-325, 2016.

[19] X. D. Zhao and J. P. Tang, "Establishment and numerical simulation of fluid-solid coupling model of coal seam under hydraulic fracturing," Mining Safety \& Environmental Protection, vol. 47 , no. 5, pp. 18-22, 2020.

[20] Q. Ye, Z. Jia, and C. Zheng, "Study on hydraulic-controlled blasting technology for pressure relief and permeability improvement in a deep hole," Journal of Petroleum Science and Engineering, vol. 159, p. 433, 2017.

[21] Y. T. Chen, J. T. Qin, and W. B. Xie, "Application study on hydraulic fracturing and deep hole pre-splitting blasting joint permeability improvement technology," Safety in Coal Mines, vol. 49, no. 8, pp. 141-144+148, 2018.

[22] W. Yang, H. Wang, Q. Zhuo et al., "Mechanism of water inhibiting gas outburst and the field experiment of coal seam infusion promoted by blasting," Fuel, vol. 251, pp. 383-393, 2019.

[23] M. H. Lin, Research on Outburst Prevention Mechanism and Technology of Integrated Blasting Injection in Working Face, China University of Mining and Technology, Xuzhou, China, 2020.

[24] X. H. Gao and M. Y. Wang, "Study on hydraulic fracturingdeep hole pre-splitting blasting composite permeability enhancement technology," Coal Science and Technology, vol. 48, no. 7, pp. 318-324, 2020. 